\title{
Secrets of the human genome disclosed
}

\section{Meeting debates ethics of revealing genetic findings.}

\section{BY ERIKA CHECK HAYDEN IN NEW YORK}

S hould people be told about any nasty surprises that scientists discover in their DNA during research projects?

The question is becoming increasingly pertinent, as thousands of people sign up for studies in which their genomes will be sequenced. But, at present, federal laws in the United States prohibit researchers from telling patients about mutations that might affect them or their families unless a certified clinical lab has confirmed the results - something that is not done in most research projects. This means that patients often do not learn about their mutations until the studies are finally published, a restriction that is meant to ensure they are not misinformed by incomplete research.

The ethical dilemmas became all too real last year for geneticist Gholson Lyon, a geneticist at the Utah Foundation for Biomedical Research in Salt Lake City. He was studying an extended family in which some of the boys had been born with a constellation of symptoms, including thick, wrinkly skin, and who ultimately died of cardiac disease before their first birthdays. By November 2010, Lyon had convincing evidence that a genetic mutation was causing the disease. That's when he learned that one of the women in the family was four months pregnant with a boy.

Lyon knew from his study that the mother carried the mutation. But he was not allowed to tell her, because the analysis had not been performed in a laboratory that was certified under the Clinical Laboratory Improvement Amendments, which aim to ensure that clinical tests are accurate and reliable.

The baby was eventually born with the disease - called Ogden syndrome - and later died, in the same week that Lyon's paper on the causative mutation was published ${ }^{1}$.

At the fourth annual Personal Genomes meeting at Cold Spring Harbor in New York last week, Lyon argued that researchers should routinely conduct their studies in certified laboratories so that they can provide participants with results as soon as possible, adding that he plans to do so himself from now on. It is a pressing issue: according to Richard Gibbs, director of the Human Genome Sequencing Center at Baylor College of Medicine in Houston, Texas, roughly 5,000

\section{$\rightarrow$ NATURE.COM}

The human genome at 10

nature.com/humangenome human genomes will be sequenced this year, with some 30,000 expected next year.

But ethicists point out that although researchers and physicians may feel obliged to disclose genetic information, they must also consider other factors. "This is not just about patients or doctors. These disclosures have societal implications that need to be considered, including downstream cost," says Ellen Wright Clayton, director of the Center for Biomedical Ethics and Society at Vanderbilt University in Nashville, Tennessee.

Genome sequencing is now starting to be used in the clinic to guide diagnosis and treatment decisions (see News Feature page 22). "These $\quad$ At the Medical College disclosures waukee, for example, have societal paediatrician and genetimplications icist David Dimmock that need to be offers genome sequencconsidered." ing to children with undiagnosed diseases. The programme is controversial because many researchers think that too little is known about how most rare genetic mutations contribute to disease for the knowledge to help patients. $\mathrm{He}$ points out, however, that a handful of cases have been reported in which sequencing has led to a cure or improved treatment ${ }^{2}$.

Using a clinically certified lab, Dimmock's team sequenced the genome of an infant with acute liver failure, and discovered that she had two mutations in a gene called Twinkle. Earlier research had linked those mutations to progressive eye and neurological conditions, and an associated liver disease. As a result, doctors determined that a liver transplant - a standard treatment for acute liver failure - would not help the infant, and recommended against it ${ }^{3}$. She died when she was 6 months old.

"This was not a happy ending - but in a sense it was," says Dimmock. Disclosing the genetic information spared the infant from spending her remaining few months recovering from a gruelling, unnecessary transplant, he says, and saved a scarce liver for a child who might benefit from it more.

1. Rope, A. F. et al. Am. J. Hum. Genet. 89, 28-43 (2011).

2. Bainbridge, M. N. et al. Sci. Transl. Med. 3, 87re3 (2011).

3. Goh, V. et al. J. Pediatr. Gastroenterol. Nutr. http:// dx.doi.org/10.1097/mpg.0b013e318227e53c (2011). 